\title{
Rancang Bangun Sistem Validasi Kehadiran Perkuliahan dengan Metode K-Nearest Neighbor Berbasis Aplikasi Perangkat Bergerak
}

\author{
Latifa Nurrohman, Adian dan Titi Ciptaningtyas, Hening. Sunaryono, Dwi. \\ Departemen Teknik Informatika, Fakultas Teknologi Informasi, Institut Teknologi Sepuluh Nopember \\ (ITS) \\ e-mail: henning@if.its.ac.id
}

\begin{abstract}
Abstrak-Perkembangan teknologi informasi di dunia semakin cepat, khususnya pada teknologi perangkat bergerak dan internet. Akses dan pengambilan informasi dikatakan semakin mudah dan cepat diakses melalui penggunaan perangkat bergerak dan web. Perkembangan ini juga mempengaruhi data sebagai validasi menggantikan kode sandi (password). Validasi merupakan sebuah proses yang wajib ada dimana diperlukan sebuah kebenaran data atau informasi, salah satunya adalah proses validasi kehadiran. Proses validasi sudah banyak diterapkan seiring dengan perkembangan teknologi informasi misalnya validasi kehadiran dengan menggunakan alat yang menerima inputan metode fingerprint, validasi kehadiran menggunakan deteksi suara, dan lain-lain. Namun kelemahan dari penerapan yang sudah ada adalah kurangnya fleksibilitas. Fleksibilitas yang dimaksud adalah teknologi yang digunakan tidak bisa berpindah tempat dan diakses kapanpun. Oleh karena itu, studi ini akan mengimplementasikan sebuah aplikasi mobile validasi kehadiran berbasis android. Aplikasi validasi kehadiran yang telah dibuat sudah dibatasi ruang lingkup penggunaannya. Pengguna dari aplikasi ini adalah mahasiswa Teknik Informatika ITS. Proses validasi kehadiran pada aplikasi ini mengimplementasikan metode pencocokan lokasi mahasiswa terhadap kelas matakuliah berlangsung dan QR Code dari masing-masing kelas. Selanjutnya, lokasi yang didapatkan dari mahasiswa akan diklasifikan dengan menggunakan algoritma K-Nearest Neighbors. Selain dengan algoritma K-Nearest Neighbors, data lokasi mahasiswa juga akan diklasifikasikan dengan metode rata-rata dan metode regresi linier. Prinsip kerja dari aplikasi ini akan membandingkan metode KNN dengan kedua metode tersebut. Kemudian, ditemukan kesamaan hasil dari ketiga metode. Apabila ketiga metode mendapatkan hasil yang sama, maka dapat dipastikan lokasi mahasiswa dengan tingkat akurasi yang tinggi.
\end{abstract}

Kata Kunci-Absensi, Validasi Kehadiran, Lokasi, QR Code, KNN, Simple Average, Regresi Linier, Aplikasi Perangkat Bergerak.

\section{PENDAHULUAN}

P ERKEMBANGAN teknologi informasi di dunia semakin cepat, khususnya pada teknologi perangkat bergerak dan internet. Akses dan pengambilan informasi dikatakan semakin mudah dan cepat diakses melalui penggunaan perangkat bergerak dan web. Perkembangan ini juga mempengaruhi data sebagai validasi menggantikan kode sandi (password). Validasi merupakan sebuah proses yang wajib ada dimana diperlukan sebuah kebenaran data atau informasi, salah satunya adalah proses validasi kehadiran. Proses validasi sudah banyak diterapkan seiring dengan perkembangan teknologi informasi misalnya validasi kehadiran dengan menggunakan alat yang menerima inputan metode fingerprint, validasi kehadiran menggunakan deteksi suara, dan lain-lain. Namun kelemahan dari penerapan yang sudah ada adalah kurangnya fleksibilitas dari penerapan ini. Fleksibilitas yang dimaksud adalah teknologi yang digunakan tidak bisa berpindah tempat dan diakses kapanpun. Sehingga, untuk memenuhi dan menghilangkan kelemahan tersebut, maka dibuatlah sistem validasi kehadiran mahasiswa berbasis perangkat bergerak.

Sistem validasi kehadiran mahasiswa merupakan proses pencatatan kehadiran mahasiswa di kelas. Dengan adanya validasi kehadiran maka dapat membuktikan bahwa mahasiswa tersebut telah berada di dalam kelas. Validasi kehadiran dapat dilakukan dengan berbagai cara. Di Teknik Informatika ITS, sistem validasi kehadiran mahasiswa dilakukan secara manual yaitu melakukan tanda tangan di kertas validasi kehadiran kelas. Hal ini menimbulkan celah kelemahan yaitu terjadi kecurangan dalam validasi kehadiran atau disebut titip absen. Titip absen merupakan kejadian dimana mahasiswa meminta teman satu kelas untuk menandatangani absen pada matakuliah tertentu, sehingga mahasiswa tersebut tidak perlu datang untuk menghadiri kelas. Oleh karena itu, diperlukan suatu sistem yang dapat digunakan untuk mengatasi kecurangan dalam validasi kehadiran.

Aplikasi validasi kehadiran yang sudah dibuat telah dibatasi ruang lingkup penggunanya. Pengguna dari aplikasi ini adalah mahasiswa Teknik Informatika ITS. Proses validasi kehadiran pada aplikasi ini mengimplementasikan metode pencocokan lokasi mahasiswa terhadap kelas matakuliah berlangsung dan $Q R$ Code dari masing-masing kelas. Selanjutnya, lokasi yang didapatkan dari mahasiswa akan diklasifikasikan dengan menggunakan algoritma KNearest Neighbors, Simple Average, dan Regresi Linier. Ketiga metode ini akan dibandingkan dan dicari kesamaan hasilnya.

Hasil yang diharapkan dari pengerjaan studi ini berupa aplikasi perangkat bergerak yang menggantikan proses validasi kehadiran mahasiswa dari sistem manual melalui tanda tangan pada kertas presensi kehadiran kelas menjadi sistem online dengan metode pencocokan lokasi mahasiswa pada aplikasi mobile. Selain itu, dengan aplikasi ini diharapkan juga dapat memberikan kebenaran data absen (data validation) serta mempermudah pemantauan kehadiran mahasiswa di kelas untuk orang tua atau wali mahasiswa dan 
juga dosen wali di jurusan Teknik informatika ITS.

\section{METODOLOGI}

\section{A. Aplikasi Perangkat Bergerak}

Aplikasi perangkat bergerak atau mobile applications adalah pengembangan aplikasi untuk perangkat genggam seperti PDA, asisten digital perusahaan atau telepon genggam, smartphone dan sebagainya. Aplikasi ini sudah ada pada telepon selama manufaktur, atau di download oleh pelanggan dari toko aplikasi dan dari distribusi perangkat lunak mobile platform yang lain[1].

Platform smartphone terpopuler yang mendukung aplikasi perangkat bergerak saat ini adalah Android, iOS, Windows Phone dan BlackBerry[2].

\section{B. Android}

Android adalah software untuk perangkat mobile yang mencakup sistem operasi, middleware dan aplikasi kunci. Pengembangan aplikasi pada platform Android menggunakan bahasa pemrograman Java. Serangkaian aplikasi inti Android antara lain klien email, program SMS, kalender, peta, browser, kontak, dan lain-lain[3].

\section{Global Positioning System (GPS)}

GPS (Global Positioning System) atau sistem peletakkan adalah sistem navigasi yang berbasiskan satelit yang saling berhubungan yang berada di orbitnya. Satelit-satelit itu milik Departemen Pertahanan (Department of Defense) Amerika Serikat yang pertama kali diperkenalkan mulai tahun 1978 dan pada tahun 1994 sudah memakai 24 satelit[4].

\section{Application Programming Interface (API)}

API atau Application Programming Interface adalah sekumpulan perintah, fungsi, serta protocol yang dapat digunakan oleh programmer saat membangun perangkat lunak untuk sistem operasi tertentu. API memungkinkan programmer untuk menggunakan fungsi standar untuk berinteraksi dengan sistem operasi. API juga dapat menjelaskan cara sebuah tugas tertentu dilakukan. Sebuah API juga dapat digunakan untuk menspesifikasikan cara komponen aplikasi saling berinteraksi. Dengan bahasa yang lebih sederhana, API adalah fungsi-fungsi pemrograman yang disediakan oleh aplikasi atau layanan agar layananan tersebut bisa di integrasikan dengan aplikasi yang dibuat. Di dalam pemrograman android, API biasanya digunakan untuk mempermudah pertukaran data dari atau ke dalam server[5].

\section{E. Quick Response Code (QR Code)}

Kode QR (Quick Response) merupakan bentuk evaluasi dari barcode yang biasanya kita lihat pada sebuah produk. Kode QR berbentuk jajaran persegi berwarna hitam berbentuk seperti barcode tetapi dengan tampilan lebih ringkas[6].

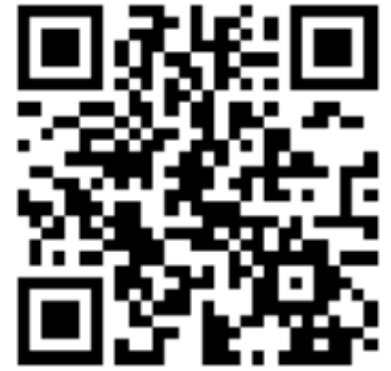

Gambar 1. Contoh QR Code

Bar code adalah metode pengumpulan data yang cepat, mudah, akurat dan otomatis. Barcode memungkinkan produk dilacak dengan efisien dan akurat menggunakan sistem entri data manual. Barcode scanner hanya digunakan untuk mengenali barcode, dan harga barcode scanner itu mahal. Kini, ponsel bisa menerapkan banyak aplikasi baru, seperti pengambilan foto dan pemotretan film dengan menggunakan kamera yang tersedia. Jadi, pendekatan yang menarik adalah melakukan scan barcode dengan kamera mereka dan menguraikannya dengan perangkat lunak yang berjalan di ponsel[7].

\section{F. $K$ - Nearest Neighbors $(K N N)$}

Algoritma K-Nearest Neighbor (KNN) merupakan sebuah metode untuk melakukan klasifikasi terhadap objek berdasarkan data pembelajaran yang jaraknya paling dekat dengan objek tersebut. KNN termasuk algoritma supervised learning dimana hasil dari query instance yang baru diklasifikan berdasarkan mayoritas dari kategori pada KNN. Kelas yang paling banyak muncul itu yang akan menjadi kelas hasil klasifikasi. Tujuan dari algoritma ini adalah mengklasifikasikan objek baru berdasarkan atribut dan training sample[8].

Algoritma K- Nearest Neighbor menggunakan klasifikasi ketetanggaan (neighbor) sebagai nilai prediksi dari query instance yang baru. Algoritma ini sederhana, bekerja berdasarkan jarak terpendek dari query instance ke training sample untuk menentukan ketetanggaannya[9].

\section{G. Metode Rata-Rata atau Simple Average (SA)}

Simple Average atau metode rata-rata merupakan metode yang mencari nilai tengah dari sekumpulan data. Caranya adalah dengan menjumlahkan seluruh data (SUM), lalu membagi dengan banyaknya data (n) seperti pada rumus[10]:

$$
F_{n}=\frac{X_{1}+X_{2}+X_{3}+\ldots .+X_{n}}{n}
$$

Gambar 2. Rumus Metode Rata-Rata

\section{H. Metode Regresi Linier}

Regresi linier adalah metode statistika yang digunakan untuk membentuk model hubungan antara variabel terikat (dependen; respon; Y) dengan satu atau lebih variabel bebas (independen, prediktor, X). Apabila banyaknya variabel bebas hanya ada satu, disebut sebagai regresi linier sederhana, sedangkan apabila terdapat lebih dari 1 variabel bebas, disebut sebagai regresi linier berganda[11]. 


\section{UJI COBA}

\section{A. Kondisi Uji Coba}

Kondisi uji coba menjelaskan tentang kondisi yang harus dipenuhi untuk menjalankan uji coba aplikasi. Kondisi uji coba merupakan pemilihan pengguna dan smartphone yang dijelaskan sebagai berikut:

Table 1.

Spesifikasi Smartphone untuk Uji Coba

\begin{tabular}{|c|c|c|c|c|c|}
\hline No & NRP & Smartphone & Seri Android & RAM & $\begin{array}{l}\text { Seri } \\
\text { GPS }\end{array}$ \\
\hline 1 & $\begin{array}{l}511310 \\
0051\end{array}$ & Sony C5 & $\begin{array}{l}\text { OS } 6 \\
\text { Marshmallow }\end{array}$ & $2 \mathrm{~GB}$ & $\begin{array}{l}\text { A- } \\
\text { GPS }\end{array}$ \\
\hline 2 & $\begin{array}{l}511310 \\
0075\end{array}$ & $\begin{array}{l}\text { Samsung } \\
\text { Note } 3\end{array}$ & $\begin{array}{l}\text { OS } 6 \\
\text { Marshmallow }\end{array}$ & $3 \mathrm{~GB}$ & $\begin{array}{l}\text { A- } \\
\text { GPS }\end{array}$ \\
\hline 3 & $\begin{array}{l}511310 \\
0128\end{array}$ & $\begin{array}{l}\text { Sony Xperia } \\
\text { Z5 }\end{array}$ & OS 7 Nougat & $3 \mathrm{~GB}$ & $\begin{array}{l}\text { A- } \\
\text { GPS }\end{array}$ \\
\hline 4 & $\begin{array}{l}511310 \\
0062\end{array}$ & $\begin{array}{l}\text { Xiaomi } \\
\text { Redmi Note } 2\end{array}$ & OS 5 Lolipop & $2 \mathrm{~GB}$ & $\begin{array}{l}\text { A- } \\
\text { GPS }\end{array}$ \\
\hline 5 & $\begin{array}{l}511310 \\
0072\end{array}$ & Oppo A37 & OS 5 Lolipop & $2 \mathrm{~GB}$ & $\begin{array}{l}\text { A- } \\
\text { GPS }\end{array}$ \\
\hline 6 & $\begin{array}{l}511310 \\
0143\end{array}$ & Samsung J2 & OS 5 Lolipop & $1 \mathrm{~GB}$ & $\begin{array}{l}\text { A- } \\
\text { GPS }\end{array}$ \\
\hline 7 & $\begin{array}{l}511310 \\
0173\end{array}$ & $\begin{array}{l}\text { Sony Xperia } \\
\text { Z1 Compact }\end{array}$ & OS 5 Lolipop & $2 \mathrm{~GB}$ & $\begin{array}{l}\text { A- } \\
\text { GPS }\end{array}$ \\
\hline
\end{tabular}

\section{B. Data Training}

Data training yang digunakan disini adalah data lokasi tiap ruang kelas yang berada di jurusan Teknik Informatika ITS dan $Q R$ Code dari masing-masing kelas.

\section{Skenario Uji Coba}

Uji coba ini dilakukan untuk menguji apakah fungsionalitas program telah diimplementasikan dengan benar dan berjalan sebagaimana mestinya. Uji coba akan didasarkan pada beberapa skenario untuk menguji kesesuaian dan kinerja aplikasi.

Skenario pengujian terdiri dari dua skenario pengujian, yaitu:

1. Skenario melakukan pencarian terhadap lokasi ruangan IF-101.

2. Skenario melakukan pencarian terhadap lokasi ruangan IF-103.

\section{Hasil Uji Coba}

Uji coba akan dilakukan dengan dua tahap utama, yaitu pemindaian $Q R$ Code dan pencocokan lokasi.

\section{1) Pemindaian $Q R$ Code}

Sebelum melakukan proses pencarian lokasi dengan GPS, mahasiswa harus terlebih dahulu memindai $Q R$ Code dari kelas yang sesuai dengan jadwal (skenario). Hasil dari pemindaian $Q R$ Code tersebut akan digunakan untuk proses validasi dengan tanda tangan atau face recognition. $Q R$ Code yang digunakan harus di encode terlebih dahulu ke Base64 atau MD5. Selanjutnya, hasil dari pemindaian akan di-decode. Berikut merupakan $Q R$ Code untuk kelas IF-101 dan IF-102 tanpa enkripsi.

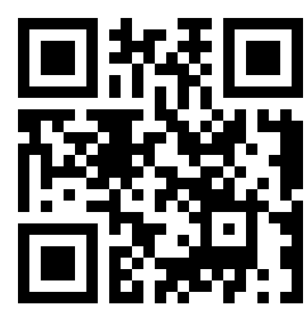

Gambar 3. QR Code untuk IF-101

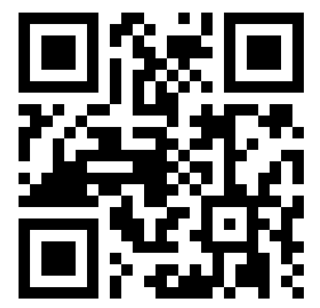

Gambar 4. QR Code untuk IF-102

2) Pencocokan Lokasi

Berikut ini merupakan hasil dari pencocokan lokasi dari ketujuh mahasiswa.

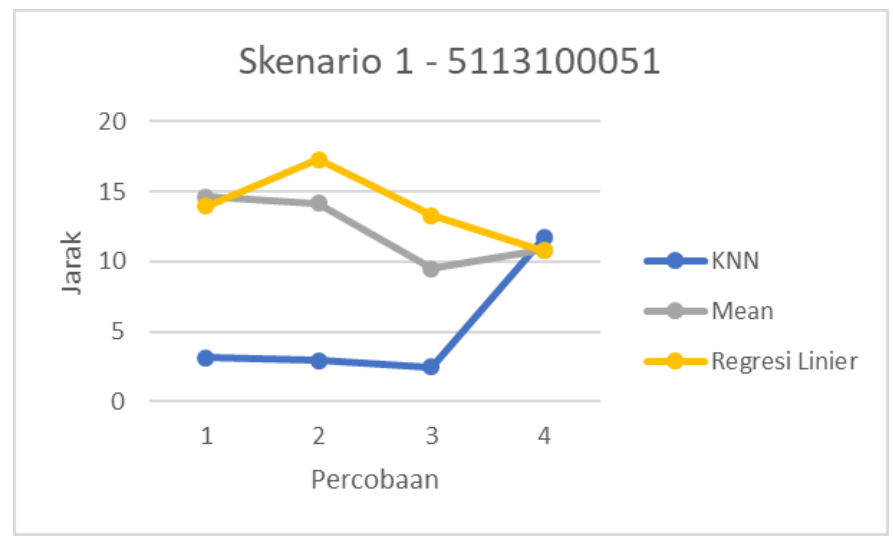

Grafik 1. Hasil Uji Coba Mahasiswa NRP 5113100051

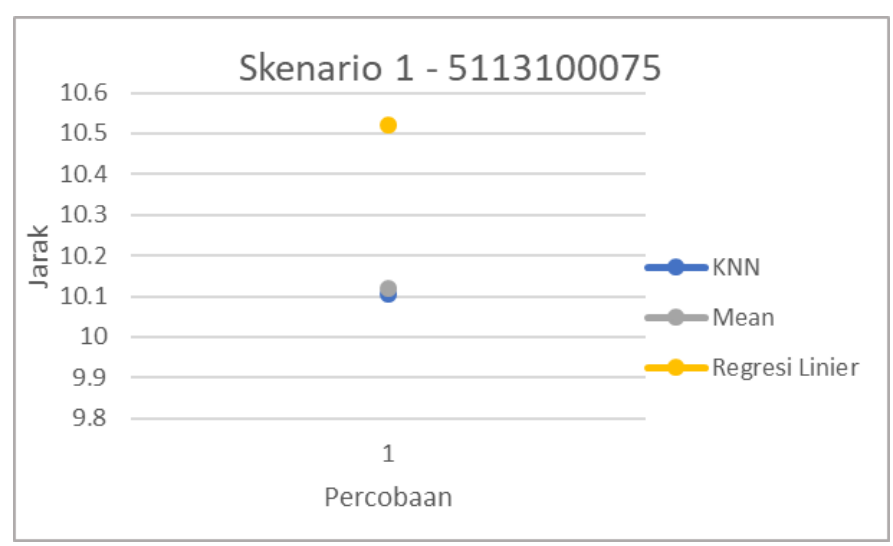

Grafik 2. Hasil Uji Coba Mahasiswa NRP 5113100075 


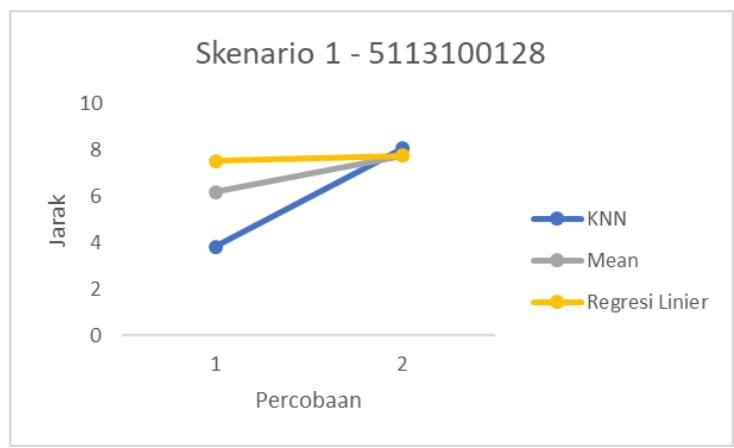

Grafik 3. Hasil Uji Coba Mahasiswa NRP 5113100128

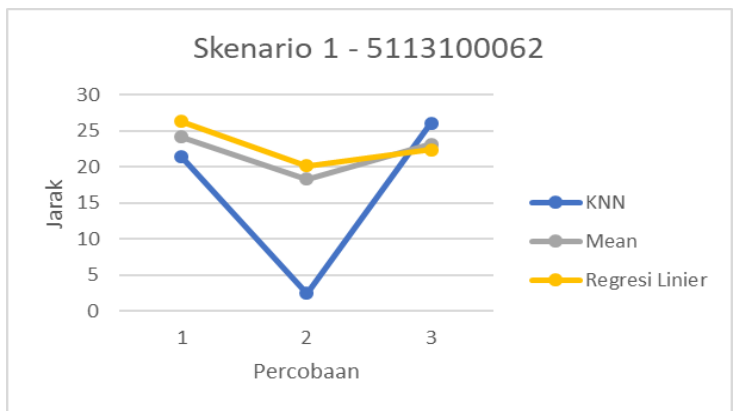

Grafik 4. Hasil Uji Coba Mahasiswa NRP 5113100062

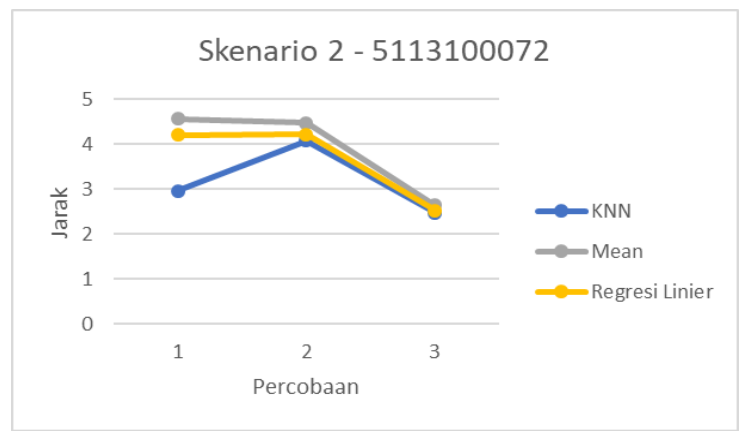

Grafik 5. Hasil Uji Coba Mahasiswa NRP 5113100072

Skenario 2 - 5113100143

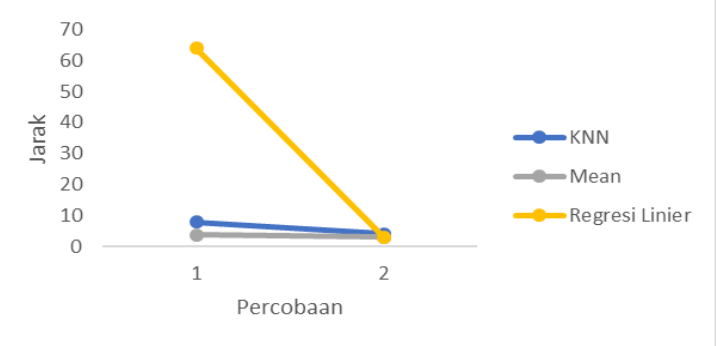

Grafik 6. Hasil Uji Coba Mahasiswa NRP 5113100143

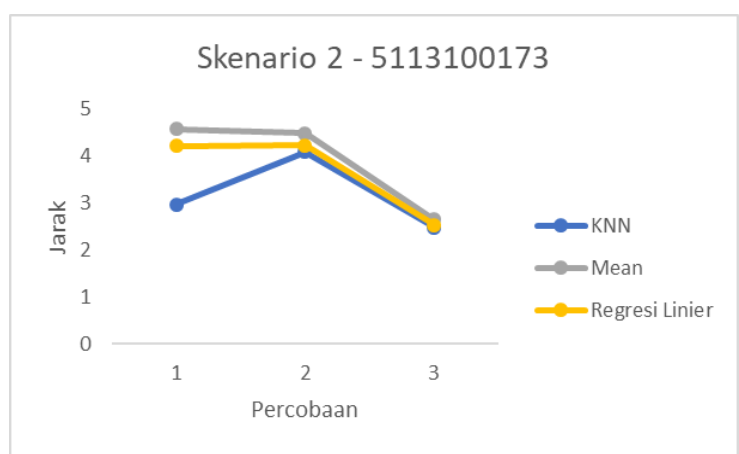

Grafik 7. Hasil Uji Coba Mahasiswa NRP 5113100173

Masing-masing grafik menggambarkan jumlah percobaan yang dilakukan untuk menemukan kelas yang cocok dengan lokasi mahasiswa saat itu. Hasil dari ketiga metode memiliki selisih jarak yang sedikit atau kecil. Hal ini membuat tingkat akurasi dapat dinyatakan tinggi dan mahasiswa tersebut dinyatakan absen karena ruang kelas dapat ditemukan, serta kelas tersebut merupakan kelas yang berada pada jurusan Teknik Informatika ITS.

\section{HASIL DAN KESIMPULAN}

Dari hasil uji coba yang telah dilakukan dapat diambil beberapa kesimpulan sebagai berikut:

1. Ketinggian atau altitude yang tidak pasti, sehingga tidak dapat digunakan untuk menentukan posisi mahasiswa secara pasti, bisa 0 , bilangan negatif, atau bilangan puluhan.

2. Hasil terbaik yang dapat digunakan sebagai lokasi mahasiswa ketika ketiga metode memiliki kode ruang kelas yang sama.

3. Jarak yang didapat dari hasil klasifikasi memiliki rata-rata 10 meter dari lokasi sebenarnya.

4. Selisih jarak dari hasil klasifikasi ketiga metode tidak lebih dari 2 meter.

\section{DAFTAR PUSTAKA}

[1] "Apa Itu Mobile Application?" [Daring]. Tersedia pada: http://cloudindonesia.com/apa-itu-mobile-application/. [Diakses: 08-Jul-2017].

[2] "4 sistem operasi smartphone paling dikenal," For Guides, 25-Feb2016. .

[3] M. I. S.-U. Surabaya, “Android: Sistem Operasi Pada Smartphone Universitas Surabaya (UBAYA)," Universitas Surabaya (Ubaya). [Daring]. Tersedia pada: http://www.ubaya.ac.id/2014/content/articles_detail/7/Android-Sistem-Operasi-pada-Smartphone.html. [Diakses: 08-Jul-2017].

[4] "Global positioning system (GPS): Overview," SpringerReference.

[5] "What is API - Application Program Interface? Webopedia." [Daring]. Tersedia pada: http://www.webopedia.com/TERM/A/API.html. [Diakses: 12-Des2016].

[6] "Jurnal/Hasil Penelitian Kementerian Perindustrian." [Daring]. Tersedia pada: http://www.kemenperin.go.id/kajian. [Diakses: 15Jul-2017].

[7] Y. Liu, J. Yang, dan M. Liu, "Recognition of QR Code with mobile phones," in Control and Decision Conference, 2008. CCDC 2008. Chinese, 2008, hal. 203-206.

[8] M. A. Banjarsari, I. Budiman, dan A. Farmadi, "PENERAPAN KOPTIMAL PADA ALGORITMA KNN UNTUK PREDIKS KELULUSAN TEPAT WAKTU MAHASISWA PROGRAM STUDI ILMU KOMPUTER FMIPA UNLAM BERDASARKAN IP SAMPAI DENGAN SEMESTER 4," KLIK - Kumpul. J. ILMU Komput., vol. 2, no. 2, hal. 159-173, Apr 2016.

[9] A. R. Alfarisi, H. Tjandrasa, dan I. Arieshanti, "Perbandingan Performa antara Imputasi Metode Konvensional dan Imputasi dengan Algoritma Mutual Nearest Neighbor," J. Tek. ITS, vol. 2, no. 1, hal. A73-A76, Mar 2013.

[10] "Kelebihan dan Kekurangan Rata-rata, Median dan Modus," Rumus Statistik. .

[11] "regresi_linier.pdf.", Rumus Statistik . 